\title{
NARRAR LA VIOLENCIA. ESPACIO Y ESTRATEGIAS DISCURSIVAS EN ESTRELLA DISTANTE DE BOLAÑO
}

Novela explosiva, desordenada, fragmentaria, pero además, novela que cuestiona y denuncia. Estrella distante tiene algo de lo que podríamos llamar estética del collage. Tiene, también, algo que la convierte en novela de la escritura, parangonable en ese sentido (y, en muchos otros) a Respiración artificial de Ricardo Piglia, ya que ambas se caracterizan por la construcción de espacios discursivos relacionados con los escenarios de las dictaduras de los años 70 y 80 en Chile y Argentina, respectivamente.

Las tesis de Lester B. Rowntree, en "The Cultural Landscape Concept in American Human Geography" (1996), ayudan a focalizar el estudio del espacio novelesco en relación con la teoría social contemporánea, estudiándolo como una matriz simbólica de la constelación cultural de Chile en la época de la dictadura pinochetista. ${ }^{1}$ Nuestra hipótesis es que los espacios funcionan como enclaves concretos pero, a su vez, simbólicos, que sirven de anclaje a los hechos narrados dispersos e inciertos, otorgando verosimilitud al relato.

Estrella distante tiene un prefacio de Bolaño por Bolaño en el que, no por casualidad, son varios los espectros que se alinean como casual constelación de estrellas distantes y muchas interrogantes que se abren respecto de quien autoriza la novela. La función del autor queda relegada (vaciada) — según confiesa el narrador del prefacio- a "preparar bebidas, consultar algunos libros"2 discutir con un compatriota "Arturo B, veterano de las guerras floridas y suicidas en África" (11) y, también, con el fantasma de Pierre Menard, autor del Quijote, según el relato de Borges: "Al dictado de sus sueños y de sus pesadillas "compusimos" la novela que el lector tiene ahora ante sî" (11), dice asumiendo, en

\footnotetext{
${ }^{1}$ De acuerdo con Rowntree, el estudio del paisaje está jugando un rol central en la geografía humana, vinculado con la teoría social contemporánea. Aunque hay diferentes agendas, Rowntree resume de esta manera los puntos en común: a) Una reformulación del concepto de cultura, enfatizando la acción humana sobre la pasividad de las teorías deterministas; b) Un énfasis en lo simbólico y en la interacción entre la acción individual y las estructuras sociales; c) Una problematización de las categorías sociales, como género, etnicidad, clase social y raza y el examen de las formas en que el paisaje está involucrado en la construcción y el mantenimiento de esas categorías; ch) La centralidad de las expresiones simbólicas en el paisaje y las conceptualizaciones metafóricas de la interacción entre hombre y medio ambiente como texto, teatro, carnaval y espectáculo para enfatizar el diseño y la manipulación del medio ambiente por las estructuras de poder; d) Una conciencia del poder del lenguaje al tomar las narrativas de paisaje (y a los autores) para reflexiones críticas que revelan los prejuicios ideológicos; e) Conexiones implícitas o explícitas con marcos teóricos como el neomarxismo, el postestructuralismo y el posmodernismo. (1996:127-159).

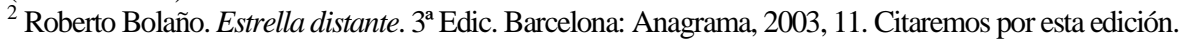




\section{Silvia Casini}

todo caso, una responsabilidad plural. El narrador del prefacio reconoce que un amigo le ha pedido una historia que fuera "espejo y explosión en sí misma" (11) y esa parece ser la clave de la poética que (des)estructura el discurso y hace que todo explote y desaparezca (o aparezca, según se lea).

Estrella distante es una novela de corte policial donde -como se anuncia en el prefacio - un autor relata, a pedido de otro, el último capítulo de La literatura nazi en América (1996), novela del mismo Bolaño, donde se narra la biografía de Ramírez Hoffman. En esa obra, Hoffman es descrito como "la estrella más brillante y enigmática (196), por lo que es dable suponer que la "estrella distante" del título alude, en forma paradójica, a la figura del represor/torturador Hoffman-Wieder. A pedido del co-autor, la novela aparece como un duplicado de sí misma: hay una narración doble, un narrador doble y un personaje que se enmascara y reduplica en su obsesión por mostrar las diferencias y similitudes en lo que se presenta como una reflexión que también es doble: ética y estética.

En Estrella distante el relato del narrador, cuya única certeza es que no tiene una versión "original" de la historia, se desenvuelve a partir de ese "no saber", que se manifiesta, entre otras estrategias, en los constantes desplazamientos del punto de vista. Sin embargo, sobre lo que el narrador no tiene dudas es respecto del lugar donde los hechos se van produciendo.

\section{DUPLICIDAD, FANTASMAGORÍA Y EXCENTRICIDAD NARRATIVA}

En Estrella distante, mientras los espacios son reconocibles, los hechos que ocurren en esos espacios son imprecisos. Los desplazamientos del punto de vista y el enmascaramiento de algunos personajes hablan de una poética de lo excéntrico. La búsqueda de Ruiz Tagle/Wieder está llena de lo que Susan Lanser denomina "lagunas diegéticas" que perturban (y hacen explotar) y dejan agujeros en la narración (1981). En este sentido la escritura parece duplicar el espacio socio-político chileno, igualmente perturbado. Precisamente, la falta de estructura de la obra (que hace que la novela sea una explosión en sí misma) convierte al texto en un vacío simbólico, un texto agujereado que es, a la vez, una cripta del olvido y de los entierros no realizados. Al respecto, en Introduction: Narrating Space, Patrica Yaeger dice

¿Hay reglas o leyes, conduciendo la narración del espacio? Si el espacio ordinario puede ser programado como heterogéneo y multidimensional, refutando la simplicidad de la narrativa lineal, si las políticas locales pueden conciliarse o estar inmersas en tropos de tragedia y romance, o en las figuras de vacío y simulacro, el espacio tiene una dimensión político-psicológica adicional. El mundo físico es también un sitio donde los deseos no correspondidos y las ideologías extrañas y las productividades ocultas son encriptadas (codificadas), de manera que toda narración del espacio debe confrontar el dilema de los enigmas geográficos, incluyendo el enigma de lo 
que permanece olvidado, o escondido, o perdido, en el confort del espacio ordinario (1996:4. Esta traducción y las siguientes son mías).

Como sugiere Yaeger para la novela, en época de la dictadura los hechos se "encriptan" (como en la exposición de fotos) o se esconden, los poetas y las poetas desaparecen (los talleres y el represor, también) pero no hay lugares para el entierro; ni siquiera cuando el narrador tiene la certeza de que han muerto.

En "Bolaño en la distancia", Enrique Vila Matas, refiriéndose a Los detectives salvajes, dice que esa novela es la historia de una generación, la de mayo del '68, que ha dejado a sus supervivientes "confundidos a todos en un mismo fracaso" (2006:102). A este fracaso generacional parece referirse el narrador de Estrella distante cuando dice: "Ésta es mi última transmisión desde el planeta de los monstruos. No me sumergiré nunca más en el mar de mierda de la literatura" (138). La tarea de escribir es percibida como un oficio de fantasmas en busca de fantasmas, en donde se puede hablar de igual a igual con Pierre Menard (algo que, de alguna manera, nos recuerda al deambular fantasmal previo a su entierro, de Juan Preciado en Pedro Páramo, de Juan Rulfo, o la presencia fantasmal de Melquíades en Cien años de soledad). La biografía de RuizTagle/Wieder es una construcción fantasmagórica que se desvanece (al autoencriptarse) como un enigma que la escritura no logra atrapar. Los sentidos (del relato) se duplican como las voces que narran, como los personajes que se entrecruzan. "Yo puedo ser el siamés del traidor" es el pensamiento con el que el narrador cierra la novela: "Entonces llegó Carlos Wieder y se sentó junto al ventanal, a tres mesas de distancia. Por un instante (en el que me sentí desfallecer) me vi a mí mismo casi pegado a él, mirando por encima de su hombro, horrendo hermano siamés, el libro que acababa de abrir" (152). Como en "El fin" de Borges, en el momento de la anagnórisis, el perseguidor se transforma en perseguido y, en ese sentido, se convierte en un perseguidor de su propia muerte.

El protagonista de Estrella distante tiene doble apellido, doble personalidad y doble vida. De una manera semejante, la novela juega con los ejes ficción/ realidad; literatura/vida; yo/el otro; fascinación/espanto; atracción/repulsión; represión/arte, en un juego donde el binarismo - como la escritura - se desplaza y explota. Celina Manzoni habla de esta perturbadora experiencia de lectura y de la "conflictiva inserción [de este texto] en el campo que hoy se expande a un iberoamericanismo todavía en vías de definición" (2006:14).

En Estrella distante, Wieder es el doble de sí mismo. Es uno (con un nombre) durante la presidencia de Allende y otro (con un nombre diferente) durante la dictadura de Pinochet, cuando se encuentra en "la cresta de la ola" (86), dispuesto a preparar "algo espectacular que (demuestre) al mundo que el nuevo régimen y el arte de vanguardia no estaban (...) reñidos" (86). Una testigo de sus actividades dice que lo admiraban por la frialdad y la distancia "que se adivinaba 


\section{Silvia Casini}

en sus ojos (...) como si detrás de sus ojos tuviera otro par de ojos" (86), los de su doble. De día se dedica a actividades sociales. De noche se encierra para preparar la exhibición de fotografías: un proyecto satánico. Las duplicaciones se exacerban: si la fotografía es una forma de duplicación, la puesta en exhibición es una forma de mostrar, por partida doble, las actividades del Teniente Coronel Wieder que también están duplicadas. La casa donde se vive también tiene su doble en la película El bebé de Rosemary, de Roman Polanski, en alusión a lo no dicho, a lo escondido, a los espacios "del horror" vacíos. Justamente, de los espacios vacíos se ocupa la nueva geografía humana. Según Yaeger

Baudrillard, Foucault y Lefebvre crean un umbral grotesco para los temas de la nueva geografía social. Ellos no sólo crean la epistemología del espacio ordinario como tragedia, sino que inventan figuras de la falsedad, del vacío, del espacio olvidado, porque estas imágenes movilizan los arquetipos comunales de calamidad o de catástrofe que parecen capturar la disforia geográfica del mundo postmoderno (1996:8).

En la novela, los espacios vacíos aseguran la legibilidad textual. Sin pretender forzar demasiado las cosas, el espacio funciona como tiempo condensado y muestra, quizás de la mejor manera (quizás como la única manera), el fluir de las agendas de los personajes.

Consultado por Carmen Boullosa, respecto de si se ha formado en la vertiente fantástica y en la realista $\mathrm{y}$, si por tanto, su literatura tiene algo de ambas, Bolaño dice que supone que su obra es realista, al mismo tiempo que refuta las supuestas divisiones en uno y otro campo diciendo que "la cuestión no reside allí sino en el lenguaje y en las estructuras, en la forma de mirar" (2006:107). La forma de mirar — de la que habla Bolaño— se duplica a través de un código de la representación inseguro que trabaja a partir de la diseminación, de los juegos de desplazamiento y de la disolución de los límites. Más allá de si se trata de literatura fantástica o realista, lo que interesa, entonces, es la forma de trabajar el lenguaje para armar un relato que es tanto una construcción del olvido como una recuperación de los "lugares de la memoria" (Lanser, 1981).

Estos "lugares de la memoria" se hacen presentes a partir de la descripción, si no minuciosa sí detallada, de un conjunto de lugares vinculados con la "constelación" Wieder. El registro de voces diferentes relacionadas con la multiplicidad de los testimonios impiden construir la figura siempre fantasmagórica del "poeta, piloto, represor" Wieder. El desorden en la demarcación de los discursos es una forma de mostrar que el referente Wieder está armado a partir de un entramado de discursos de los cuales el narrador (uno más entre tantos testigos) sólo llega a registrar algunos. Tampoco hay un eje central del relato porque el vaciamiento estructural (al igual que el vaciamiento de la autoridad diegética) es deliberado. El corrimiento, los agregados, las 
diferencias están en la base constructiva de la novela que amontona datos inciertos en una dispersión que el lector siente infinita.

A diferencia de las voces, los espacios (tanto los cerrados como los abiertos) se perciben como enclaves. Al narrar hechos vinculados con el quehacer político de la dictadura pinochetista, el relato incluye, de manera espejada, formas de lo infame, tanto en los espacios físicos como en los cuerpos y en las palabras. Junto al destino de Wieder se mezclan los destinos de aquellos que lo conocieron y están como él (pero, a la vez, en forma diferente a él), desaparecidos. El vacío y el vaciamiento se leen de varias maneras ya que, por un lado, están los cuerpos vaciados (mutilados) por Wieder, representados en sus fotografías, y, por otro, está el ocultamiento de su identidad en una forma de enmascaramiento que lo condena, como al narrador, a vivir en el exilio. Pero, lo que la novela busca es mostrar las diferencias. El vaciamiento del victimario difiere del de la víctima, aunque ambos necesiten exiliarse y aunque el narrador sienta culpas por omisión (por el vacío discursivo), porque no supo reconocer al traidor, ni denunciarlo a tiempo.

\section{LOS ESPACIOS COMO ENCLAVES SOCIO-HISTÓRICOS}

Estrella distante comienza en el contexto de la presidencia de Allende en 1971 o 1972. Si bien el dato cronológico es incierto, el dato espacial es concreto, el Chile de Allende en la ciudad de Concepción, "la llamada capital del sur" (13). El narrador no tiene autoridad diegética (sí mimética) para contar. ${ }^{3}$ Es un testigo presencial de los hechos que está tratando de recordar y reconoce sus propias limitaciones, a veces — como en la cita siguiente — adoptan una identidad plural: "En realidad, todas las suposiciones que podíamos hacer en torno a Ruiz-Tagle estaban predeterminadas por nuestros celos o tal vez nuestra envidia" (14-5), dice. Los talleres de poesía, en tiempo de Allende, son espacios que se leen como una posibilidad de vivir la utopía revolucionaria: "la llave que nos abriría la puerta de los sueños, los únicos por los cuales merecía la pena vivir" (13). Cuando el Golpe de Estado de Pinochet clausura ese espacio para la vida, los escenarios de Chile se vuelven espacios para el simulacro y ya no habrá informes de primera mano. El narrador nos va a ir contando lo que ha sabido por otros, lo que también alude a un vaciamiento de la experiencia.

El narrador describe la casa de Ruiz-Tagle a partir de lo que le cuenta otro personaje, quien siente que a la casa de Tagle le falta algo "innombrable (...) como si el anfitrión hubiera amputado trozos de su vivienda" (17). La autoamputación de su personalidad, la amputación de los cuerpos de sus víctimas (que, a su vez, se duplica en fotos) y el vaciamiento de la casa, son ejemplos de la estética (explosiva) de la novela. La descripción de la casa aparece en una carta

\footnotetext{
${ }^{3}$ Para autoridad diegética y mimética, Cfr. Susan Lanser. The Narrative Act: Point of view in Prose Fiction (1981).
} 


\section{Silvia Casini}

que Bibiano envía años después al narrador, lo que aumenta, aún más, el proceso de reduplicación del referente. Bibiano dice que "tuvo la impresión de que la casa estaba preparada" (17). Escrita en cursiva, la palabra "preparada" es un "encriptamiento" del enmascaramiento que duplica la identidad de su dueño, la del relato y refiere, además, a la película de Polanski que sirve de código compartido entre film y novela respecto del artificio escénico. La "amputación" que Bibiano supone que se ha realizado en la casa de Tagle, a la que le faltan trozos, se homologa, también, con la exposición fotográfica de mujeres amputadas, con las lagunas diegéticas (las "amputaciones" del relato) y con la incapacidad del narrador para sentirse "autorizado" a contar una historia totalizadora. La descripción de la casa desde la focalización de Bibiano incluye una serie de elementos (igualmente encriptadas): un olor "espeso" (18), "ruido en las habitaciones" (18), "paredes limpias" (19), "libros ordenados" (19) y una máquina Leyser que Tagle había usado para sacar fotos esa misma tarde a los miembros del taller de poesía (19). Los detalles de la casa son códigos (sinécdoques en el plano retórico) que relacionan el espacio concreto con el espacio exterior: las hermanas Garmendia fotografiadas por Tagle (que ya han sido asesinadas si medimos el tiempo en el momento cuando el narrador describe la casa y no en el momento cuando Bibiano la recorre); el narrador que describe a partir de lo que Bibiano le ha escrito; Bibiano y Tagle mismo; todos están incluidos en esa particular evaluación de la "artificiosidad" del lugar.

Con una impronta semejante a la del narrador, el relato de Bibiano es consistente respecto de la descripción física del espacio, pero inconsistente respecto de otros aspectos vinculados con su visita a la casa, como, por ejemplo, de qué hablaba Tagle para retenerlo en el lugar. Pero, además, todo lo que se cuenta está erosionado en su base porque el narrador reconoce que Ruiz-Tagle: "era el blanco de la envidia de Bibiano O'Ryan y de la mía propia" (22).

En el momento cuando Bibiano lo visita, Tagle está incursionando en dos talleres de poesía, el de Stein y el de Soto. Del taller de Stein no se hace una descripción física sino que se lo describe a partir de algunas situaciones que ocurren allí, pero al taller de Soto se lo describe con detalles que abundan en el tema del espejo y la duplicidad. Las clases tienen lugar en la Facultad de Medicina, "en un cuarto mal ventilado y mal amoblado, separado tan sólo por un pasillo del anfiteatro en donde los estudiantes despiezaban cadáveres en las clases de anatomía" (20). Se menciona, también, el olor del formol que los estudiantes usan para conservar los cadáveres. Los alumnos de Stein intentan "disimular" ese olor "encendiendo un cigarrillo tras otro" (20), porque la consigna, aquí, también parece ser la de enmascarar y "arreglar" artificialmente el lugar. La referencia al artificio, al simulacro, al vacío y a la atomización de los cuerpos es una repetición de los códigos con los que está armado el relato, a partir del pedido concreto expuesto en el prefacio de la necesidad de conformar un cuerpo-texto explosivo. 
Cuando la gorda Posadas, una estudiante de los talleres, le dice a Bibiano que no incluya a Tagle en la Antología que está por publicar, la razón que le da es que los poemas no parecen suyos: "Alberto es un buen poeta, pero aún no ha explotado" (24), dice Posadas. Lo que está oculto y va a explotar en el párrafo siguiente es el Golpe Militar que derroca a Allende. En ese párrafo, uno de los más breves de la novela, con una contundencia y una certeza inusual, el narrador dice: "Pocos días después llegó el golpe militar y la desbandada" (26).

Conocido el Golpe de Estado pinochetista, las Garmendia viajan de Concepción a Nacimiento. El rito de pasaje de las hermanas es narrado con detalle: la casa de los padres en Nacimiento es un lugar intocable y ellas "regresaban a la casa paterna cuando la 'vida real' adquiría visos de cierta fealdad y cierta brutalidad profundamente desagradables" (27). El pasaje aquí remeda lo que va de literatura realista a fantástica.

El narrador parece creer que cuando la "vida real" no es como se quiere, las hermanas pueden encerrarse (auto-encriptarse) en un recinto (como el de Alicia en el País de las Maravillas de L. Caroll) que las saca de la realidad. Lo que sigue es conjetural: el encierro de las Garmendia en la casa paterna, el refugio previo a la muerte, la llegada de Ruiz-Tagle: "Tuvo que ser asî" (29), dice el narrador.

A partir de aquí, el relato está armado como una película de horror en la que se decide mostrar el rostro del victimario: "Unas horas después Alberto RuizTagle, aunque ya debería empezar a llamarle Carlos Wieder, se levanta" (31), es todo lo que dice el narrador. La muerte de la tía, la irrupción de cuatro hombres que vienen a ayudarlo en la tarea de dar muerte a las hermanas Garmendia se narran sin pasión, sin gritos, sin dolor, como si se tratara de una película muda. Si la casa había sido pensada como una casa para el refugio, ahora la frontera de la casa se rompe y la noche entra y sale de la casa "efectiva y veloz" (33), tal como lo expresa el narrador.

A partir de la exposición fotográfica, Carlos Wieder desaparece y las noticias sobre él "son confusas, contradictorias, su figura aparece y desaparece en la antología móvil de la literatura chilena envuelto en brumas, se especula con su expulsión de la Fuerza Aérea chilena en un juicio nocturno y secreto" (103). En el exilio cambia de nombres y el narrador supone que es el autor de una pieza teatral que transcurre en un mundo de hermanos siameses "en donde el sadismo y el masoquismo son juegos de niños. Sólo la muerte está penalizada en este mundo y sobre ella (sobre el no-ser, sobre la nada, sobre la vida después de la vida) discurren los hermanos a lo largo de la obra" (103-4). El teatro se homologa con Estrella distante que también habla sobre el no-ser y la nada y que juega con la posibilidad, sugerida hacia el final de la novela, de que Wieder y el narrador sean siameses. ${ }^{4}$

\footnotetext{
${ }^{4}$ No lo sabemos con certeza, pero es probable que Bolaño haya leído Los siameses de Griselda Gambaro, obra que pertenece al teatro de la crueldad, donde se metaforiza la situación política argentina en los años de la dictadura (1976-1983).
} 


\section{Silvia Casini}

En síntesis, estamos frente a una novela de la dictadura con un planteo diferente al del género ya que en Estrella distante el espacio concreto del tirano (su cuerpo) está ausente. La tiranía, sin embargo, aparece marcada doblemente a partir de los espacios que "dan cuerpo" al personaje Wieder (el poeta-torturador que, al enmascararse, revela lo más infame del régimen) y, también, a partir de los desaparecidos. Los espacios cambian, hacia el final, de Chile a Europa, pero con este viaje la novela nos da una versión más de las posibilidades del "contar $a d$ infinitum" (como en Las mil y una noches) para diferir la muerte. Estrella distante se lee como una novela policial donde lo que importa no es tanto encontrar al asesino como mostrar a través de un elaborado proceso escritural, las errancias de las víctimas vivas de la dictadura (el narrador, Romero, Bibiano y tantos otros) que buscan un lugar donde sobrevivir a la catástrofe o donde ser enterrados.

Estrella distante desafía nuestros hábitos de percibir el espacio. La historia no se arma desde un comienzo hacia un fin porque, precisamente, lo que la novela cuestiona es la posibilidad de que exista un "orden del relato", un espacio que pueda ser diseñado racionalmente. ${ }^{5}$ Cuerpos esparcidos, vaciados $\mathrm{y}$ recuperados cuestionan el concepto de orden y de "autoridad". Si en otras novelas la casa es el lugar para el refugio amoroso, en Estrella distante los refugios para el amor han desaparecido. La novela cuestiona el Golpe Militar de Pinochet que ha instaurado en Chile un sistema de creencias ortodoxas - basada en un orden falso - pero el país, sin embargo, es el lugar de la memoria. El vínculo con la tierra aparece en la nostalgia de los expatriados y en la necesidad de volver, aunque sea después de muertos. Estrella distante parte del reconocimiento de que la realidad no existe fuera del discurso. Los espacios secundarios (cartas, memorias, fotos) son recortes que conforman el gran recorte que es la novela, hecha con diferentes narraciones con una experiencia espacial común de encierro, vacío, enajenación y muerte. La novela arma y desarma tejidos/tramas/cuerpos reuniendo significados que han perdido su relación natural con la experiencia y tienen, más bien, una relación artificial —en tanto simulacro— con las cosas que suponen estar nombrando.

Universidad Nacional de la Patagonia SJB* Facultad de Humanidades y Ciencias Sociales Res.: El Clarín 9469000 Comodoro Rivadavia Chubut (Argentina) silviestcas@hotmail.com

\footnotetext{
${ }^{5}$ Aludo aquí al libro de Foucault. El orden del discurso (1992) en el que el autor habla, precisamente, de los relatos como engendradores de poder.
} 


\section{BIBLIOGRAFIA}

BOLAÑO, Roberto. Estrella distante. $3^{\text {a } E d i c . ~ B a r c e l o n a: ~ A n a g r a m a, ~} 2003$.

------ La literatura nazi en América. Barcelona: Seix Barral, 1996.

------ Los detectives salvajes. Barcelona: Anagrama, 1998.

BORGES, Jorge Luis. "Pierre Menard, autor del Quijote", en Ficciones. Buenos Aires: Emecé, 1956.

BOULLOSA, Carmen. "Carmen Boullosa entrevista a Roberto Bolaño", en Manzoni, Celina (comp.). La escritura como tauromaquia. Buenos Aires: Corregidor, 2006:105-13.

FOUCAULT, Michel. El orden del discurso. Buenos Aires: Tusquets, 1992.

LANSER, Susan. The Narrative Act: Point of view in Prose Fiction. Princeton: Princeton University Press, 1981.

MANZONI, Celina. "Prólogo" a Manzoni, Celina (comp.). La escritura como tauromaquia. Buenos Aires: Corregidor, 2006.

NORA, Pierre. "Between Memory and History. Les Lieux de Mémoire", en Representations (1989):26;7-24.

ROWNTREE, Lester B. "The Cultural Landscape Concept in American Human Geography", en Earle, Carville, Mathewson, K. y Kenzer, MS. Concepts in Human Geography. Lanham MD: Rowman \& Littlefield, 1996.

VILA MATAS, Enrique. "Bolaño en la distancia", en Manzoni, Celina (Comp.) La escritura como tauromaquia. Buenos Aires: Corregidor, 2006:97-104.

YAEGER, Patricia. "Introduction: Narrating Space", en Yaeger, Patricia. (Ed.). The Geography of Identity. Ann Arbor: The University of Michigan Press, 1996. 